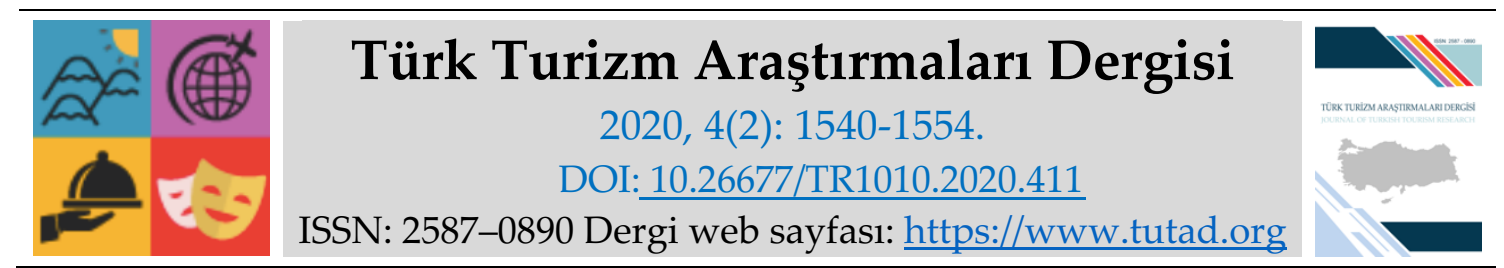

ARAȘTIRMA MAKALESI

\title{
Ilgaz Mutfak Kültürü
}

Dr. Öğr. Üyesi Ayhan DAĞDEVİREN, Çankırı Karatekin Üniversitesi, Ilgaz Turizm ve Otelcilik Yüksekokulu, Çankırı, e-posta: ayhandagdeviren@karatekin.edu.tr ORCID: https://orcid.org/0000-0003-0004-8007

Hafize TEMIZ, Lisans Öğrencisi, Çankırı Karatekin Üniversitesi, Ilgaz Turizm ve Otelcilik Yüksekokulu, Çankırı, e-posta: $161201030 @$ ogrenci.karatekin.edu.tr

ORCID: https://orcid.org/0000-0002-2925-769X

Tuğba TAVŞANOĞLU, Lisans Öğrencisi, Çankırı Karatekin Üniversitesi, Ilgaz Turizm ve Otelcilik Yüksekokulu, Çankırı, e-posta: 161201036@ogrenci.karatekin.edu.tr

ORCID: https://orcid.org/0000-0001-5978-8822

Burak ŞİRINN, Lisans Öğrencisi, Çankırı Karatekin Üniversitesi, Ilgaz Turizm ve Otelcilik Yüksekokulu, Çankırı, e-posta: 161201072@ogrenci.karatekin.edu.tr

ORCID: https://orcid.org/0000-0002-6217-9419

$\ddot{O} z$

Bu araştırmanın amacı, Ilgaz ilçesinin mutfak kültürünü analiz etmek ve Ilgaz ilçesinin gastronomi turizmi açısından gelişimine katkıda bulunmaktır. Araştırmanın örneklemini Ilgaz ilçesinde doğan ve yaşayan 60 yaş ve üstü 11 kadın oluşturmaktadır. Araştırma verilerinin toplanmasında yapılandırılmış görüşme yöntemi kullanılmıştır. Ses kayıt cihazı ile kaydedilen araştırma verileri, çözümlenerek metin haline dönüştürülmüştür. Araştırma verilerinin analizinde betimsel analiz yaklaşımından yararlanılmıştır. Araştırma sonucunda Ilgaz'ın birçok gastronomik değerinin olduğu ve bunlardan ev yapımı sucuk ve pastırma ile kül çöreğinin unutulmaya yüz tuttuğu, Ilgaz taş fırınlarının tarihinin tam olarak bilinmediği, özellikle Ramazan aylarında bu fırınların aktif olarak kullanıldığı ve hâlâ varlıklarını sürdürdükleri, katılımcıların yemek yapmaya genel olarak 10 yaşın üstünde ve isteyerek başladıkları ortaya çıkmıştır. Ayrıca araştırma sonucunda katılımcıların kış öncesi gıdaları kuruttukları (genellikle fasulye, elma, erik), turşu yaptıkları, ağırlıklı olarak reçel, tarhana, erişte ve perişka yaptıkları belirlenmiştir. Diğger taraftan araştırma sonucunda katılımcıların tümünün geçmişte yer sofralarında yemeklerini yedikleri, K4 dışındaki tüm katılımcıların tek bir tabakta ve tahta kaşıklarla yemeklerini yedikleri bulgusuna ulaşılmıştır. Ayrıca katılımcıların çoğunun bayramlarda geleneksel yemek kültürünün devam ettiği görüşünde olduğu, buna karşın dügün ve cenazelerde geleneksel yemek kültürünün devam etmediği görüşünde olduğu bulgusuna ulaşılmıştır. Ayrıca araştırma sonucunda katılımcıların çoğunun yeni neslin Ilgaz mutfak kültürüne karşı ilgili ve bu kültürü devam ettirme konusunda gayretli oldukları görüşünde olduğu ortaya çıkmıştır.

Anahtar Kelimeler: Ilgaz, Mutfak Kültürü, Ilgaz Mutfağı, Gastronomi Turizmi.

Makale Gönderme Tarihi: 16.02.2020

Makale Kabul Tarihi: 15.04.2020

Önerilen Atıf:

Dağdevien, A., Temiz, H., Tavşanoğlu, T. ve Şirin, B. (2020). Ilgaz Mutfak Kültürü, Türk Turizm Araştırmaları Dergisi, 4(2): 1540-1554.

(C) 2020 Türk Turizm Araştırmaları Dergisi. 


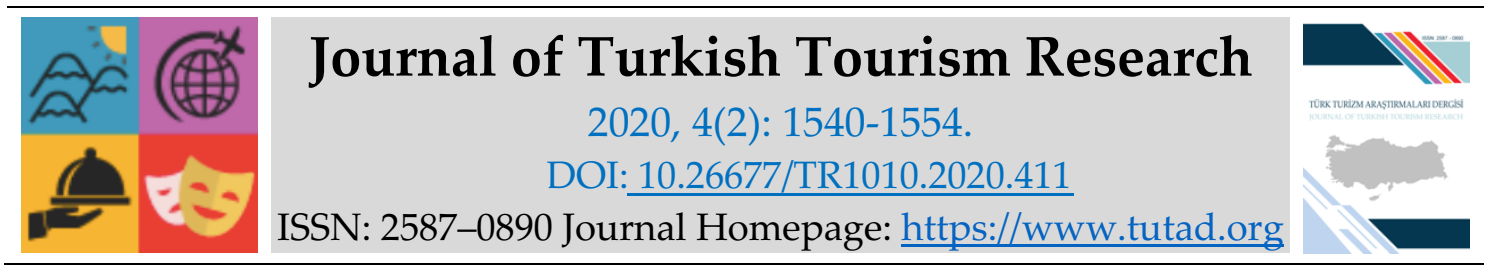

RESEARCH PAPER

\title{
Ilgaz Cuisine Culture
}

Assistant Prof. Dr. Ayhan DAĞDEVİREN, Çankırı Karatekin University, Ilgaz School of Tourism and Hotel Management, Çankırı, e-mail: ayhandagdeviren@karatekin.edu.tr ORCID: https://orcid.org/0000-0003-0004-8007

Hafize TEMIZ, Undergraduate Student, Çankırı Karatekin University, Ilgaz School of Tourism and Hotel Management, Çankırı, e-mail: 161201030@ogrenci.karatekin.edu.tr

ORCID: https://orcid.org/0000-0002-2925-769X

Tuğba TAVŞANOĞLU, Undergraduate Student, Çankırı Karatekin University, Ilgaz School of Tourism and Hotel Management, Çankırı, e-mail: 161201036@ogrenci.karatekin.edu.tr

ORCID: https://orcid.org/0000-0001-5978-8822

Burak ŞİRIN, Undergraduate Student, Çankırı Karatekin University, Ilgaz School of Tourism and Hotel Management, Çankırı, e-mail: 161201072@ogrenci.karatekin.edu.tr ORCID: https://orcid.org/0000-0002-6217-9419

\begin{abstract}
The aim of this research is to analyze the cuisine culture of Ilgaz district and contribute to the development of Ilgaz district in terms of gastronomy tourism. The sample of the research consists of 11 women aged 60 and over, born and living in Ilgaz district. Structured interview method was used to collect research data. The research data recorded by the voice recorder were analyzed and converted into text. Descriptive analysis approach was used in the analysis of research data. As a result of the research it was revealed that Ilgaz has many gastronomic values and among these, home-made sausage and pastrami and kül çöreği are forgotten, the history of Ilgaz stone ovens is not known exactly, especially during Ramadan, these ovens are actively used and still exist, and the participants generally started cooking over the age of 10 and willingly. In addition, as a result of the research, it was determined that the participants dried food (usually beans, apples, plums), pickled, made mainly jam, tarhana, noodle and perişka before winter. On the other hand, as a result of the research, it was found that all of the participants had their meals on the ground tables in the past, and all participants except K4 had their meals on a single plate and wooden spoons. In addition, although it was found that most of the participants thought that traditional food culture continued during the feasts and that traditional food culture did not continue at weddings and funerals. In addition, as a result of the research, it was revealed that most of the participants thought that the new generation is interested in Ilgaz cuisine culture and they are diligent to continue this culture.
\end{abstract}

Keywords: Ilgaz, Cuisine Culture, Ilgaz Cuisine, Gastronomy Tourism.

Received: 16.02 .2020

Accepted: 15.04 .2020

Suggested Citation:

Dağdevien, A., Temiz, H., Tavşanoğlu, T. and Şirin, B. (2020). Ilgaz Cuisine Culture, Journal of Turkish Tourism Research, 4(2): 1540-1554.

(C) 2020 Türk Turizm Araştırmaları Dergisi. 


\section{GİRIŞ}

Kültürel miras, turistler için önemli çekiciliklerden biridir (Dilek ve Kesgingöz, 2016: 60). Geçmişten geleceğe aktarılarak gelen en zengin kültürel miras olan mutfak kültürü, beslenmeyi sağlayan yemek, yiyecek-içecek türleri ve bunların hazırlanma, pişirilme, saklanma ve tüketilme sürecini, buna bağlı mekân ve ekipmanı, yeme-içme geleneği ile bu çerçevede gelişen inanış ve uygulamalardan oluşan bütünsel ve kendine özgü bir yapıyı ifade eder (Alyakut ve Polat Üzümcü, 2017: 1839; Çevik, 2004). İnsanların, mutfak kültürünün oluşumunda bulundukları coğrafya, iklim ve hayatta kalma mücadelesi etkilidir. Dünyada ün yapmış olan mutfaklar; tanınmışlık, özgünlük ve çeşitlilik özelliğiyle kendisini göstermektedir (Özgen, 2017: 7). Türk mutfağı, Çin ve Fransız mutfaklarıyla birlikte dünyanın üç ünlü mutfağından biri olarak kabul edilmektedir. Türk Mutfağı, Orta Asya'dan bu yana yüzyıllar süren gelişimi içinde mutfak mimarisi, araç gereçleri, sofra düzenleri, servis usulleri, pişirme yöntemleri, yemek çeşitleri, kış için hazırlanan yiyecek ve içecekleriyle kendine has bir üsluba sahiptir. Son şeklini ise Anadolu'da almıştır. Anadolu'nun geniş bir coğrafyaya, farklı iklimlere ve farklı tarımsal üretime sahip oluşu, mutfağına da yansımış ve yöresel farklılıklar ortaya çıkmıştır (Durlu Özkaya ve Cömert, 2017: 3). Yöreden yöreye farklılaşan lezzetleri barındıran yemek yeme ve içme biçimleri; özel gün, kutlama ve törenleriyle de ayrı bir anlam, hatta kutsallık taşımaktadır (Sürücüoğlu ve Özçelik, 2007: 1292).

Giderek birbirine benzeyen kültürlere karşı yerel bir kültür ve bu kültürü yansıtan gastronomik değerler, destinasyonların pazarlanmasında farklılıklar yaratabilmek açısından önem taşımaktadır. İnsanların yemek yemek ve gıda deneyimleri için belirli bir destinasyona seyahat etmelerini ifade eden gastronomi turizminin sezonluk özellik taşımaması-her mevsimde yapılabilir nitelikte olması-destinasyonlar açısından ayrıca bir önem taşımaktadır (Zağralı ve Akbaba, 2015: 6633; Karim ve Chi, 2010: 532-533).

İster dolaylı isterse de doğrudan olsun yerel mutfaklar, yerel kültürün tanıtımında çok önemli bir rol oynamaktadır ve bu durum, bölgenin gastronomi turizmi açısından markalaşmasında etkin olmasını sağlamaktadır (Deniz ve Atışman, 2017: 59). Türkiye'de çok sayıda yerleşim birimi, mutfak zenginliği ile gastronomi turizminde markalaşma potansiyeline sahiptir (Yenipınar ve Kart Gölgeli, 2015: 314). Çankırı ve yöresi, bu açıdan önemli bir konuma sahiptir. Çankırı ve yöresinde mutfak kültürü, genelde yaran kültürüne dayanan ortak özellikler taşır ve "Kız anadan öğrenir sofra düzmeyi, oğlan babadan öğrenir sohbet gezmeyi" sözü ile kadınların mutfak işlerinde ön plana çıktığı görülür (Balcı vd., 2005: 85).

$\mathrm{Bu}$ araştırmada Çankırı'nın Ilgaz ilçesinin mutfak kültürünü analiz etmek ve Ilgaz ilçesinin gastronomi turizmi açısından gelişimine katkıda bulunmak amaçlanmaktadır. Ilgaz, tarih boyunca coğrafik ve stratejik önemi nedeni ile insanların ilgi alanı olmuş ve medeniyetleri kendisine çekmiştir. Kaşkalar, Hititler, Dorlar, Kimmerler, Lidyalılar, Perslerin hüküm sürdüğü Ilgaz, Büyük İskender'in hâkimiyetine geçtikten sonra Romalılar, Danişmentliler, Bizanslılar, Selçuklular, Candaroğulları ve Osmanlıların egemenlik kurduğu bir bölge olmuştur (Çakırsipahi, 2002: 15-16). Bu kültürlerin etkisiyle zenginleşen Ilgaz, bugünkü konumuna ulaşmıştır.

Kültürel mirasın korunarak geleceğe aktarılması, sürdürülebilir turizmin temel amaçları arasında yer alır. Kültürel mirasın bileşenlerinden olan mutfak kültürü, özellikle şehirleşmenin etkisiyle bazı noktalarda unutulma ve kaybolma tehlikesiyle karşı karşıyadır. Gastronomi turizminin gelişmesi, mutfak kültürünün ortaya çıkarılmasına ve korunmasına da katkı sağlayacaktır (Tuna ve Özyurt, 2018: 76). 


\section{LİTERATÜR İNCELEMESİ}

İnsanların doğumdan ölüme yol aldıkları süreç içinde beslenmek durumunda olması, ilk çağlardan bu yana yeme-içme ile ilgili birtakım kurallar belirlemelerine neden olmuştur. Bu kurallar, zamanla toplumların kendi yapılarına ve değer yargılarına uygun gelenek, görenek, dinsel inançlar, töre ve törenlerle de birleşerek toplumun kendine has beslenme ve mutfak kültürünü ortaya çıkarmıştır (Sürücüoğlu ve Özçelik, 2007: 1290).

Türkler, tarih sahnesine çıktıkları andan itibaren beslenmeye önem vermişlerdir. Beslenme, sosyal hayatlarında önemli rol üstlenmiş hususlardan biri olarak öne çıkmıştır. Bu husus, o kadar önemli olmuştur ki Türk idarecileri, öncelikle milletini aç ve çıplak bırakmamayı ana ilke edinerek ülke yönetimini üstlenebilmişlerdir (Talas, 2005: 275). Türkler, Arapça matbah kelimesinden dillerine geçen ve pişirilen yer, pişirme yeri anlamına gelen mutfak kelimesi yerine Uygurlar zamanından beri aşlık, aşevi, aş taamı, aş ocağı gibi kelimeleri kullanmışlardır. Geleneksel Türk mutfağı, bahçe içinde ve genellikle eve bitişik, ama evin dışında bir yere inşa edilmiştir. Bugün bile Anadolu'nun bazı noktalarında bu uygulamanın devam ettiği görülmektedir. Modern mutfaklardaki çeşitli pişirme aygıtlarına gelinceye kadar Türkler; mutfaklarında fırın, tandır, maltız ve kuzine gibi sabit ve seyyar çeşitli pişirme aygıtlarını kullanmışlardır (Kut, 2002: 215).

Türk mutfak kültürü, Orta Asya'dan günümüze kadar gelen tarihsel bir süreci kapsamaktadır. Et ve fermente süt ürünlerinden oluşan beslenme çeşidi Orta Asya'dan, gelişen tarım sistemine bağlı olarak tahıla dayalı beslenme kültürü Mezopotamya' dan, meyve sebze türleri ile çeşitlenen beslenme sistemi ise Akdeniz ve Ege bölgelerinden gelerek Türk mutfak kültürünün temelini belirlemiştir. Göçebe kültüründen Anadolu, Selçuklu ve Osmanlıya dayanan geçmişiyle Türk mutfak kültürü, günümüze kadar gelişmiş ve olgunlaşmıştır (Güler, 2010: 24-25; Durlu Özkaya ve Cömert, 2017: 7-8). Türkiye' de yerel mutfakların özgün etkilerini içinde barındıran köklü ve çok yönlü bir mutfak kültürü varlığını sürdürmektedir (Çevik, 2004). Yerel mutfak, bir destinasyonun kimliğine katkı sağlayan, birçok turistin seyahat deneyiminin ayrılmaz bir parçasıdır (Jalis vd., 2014: 102-103). Diğer bir ifadeyle yerel mutfak, bir destinasyonun somut olmayan mirasının temel bir dışavurumunu temsil eder ve onun tüketimi ile turistler gerçekten otantik bir kültürel deneyim kazanabilirler (Okumuş vd., 2007: 253). López-Guzmán ve SánchezCañizares (2011), çalışmalarında turistlerin İspanya'nın Kordoba şehrini tercih etmelerinde yerel mutfağın birinci veya ikinci faktör olduğu bulgusuna ulaşmışlardır. Şahin (2019: 2552), çalışmasında Fransa'yı ziyaret eden turistlerin çok büyük bir bölümünün bölgesel/yerel şarapların, peynirlerin, pasta ya da yemeklerin tadına bakmadan dönmediğini, yerel gastronomi deneyimlerini tatillerinin önemli bir parçası olarak gördügünü ifade etmiştir. Son yıllarda yerel mutfağa ilginin artmasıyla birlikte birçok destinasyon, temel turizm ürünü olarak gıdaya odaklanmaktadır (Karım ve Chi, 2010: 532).

Başta teknoloji olmak üzere pek çok alanda yaşanan gelişmeler, mutfak kültürlerinin etkileşim içerisine girmesini sağlamıştır. Çoğunlukla olumlu olarak algılanan bu durum, yerelleşmeden ve geleneksel değerlerden uzaklaşmayı da beraberinde getirmiştir. Bu durumun da etkisiyle birçok araştırmacı, yerel mutfak çalışmalarına odaklanmıştır (Çakıcı ve Zencir, 2018: 286).

Artun (2001), çalışmasında 14 kişiyle görüşerek Adana'da törenlere, adaklara, özel günlere ait inançlar, pratikler ve bunlara bağlı mutfak kültürünü değerlendirmiştir. Yalçın Çelik (2010), çalışmasında 65 yaş ve üstü 4 kişi ile görüşerek Bolu'nun Mengen ilçesinde özel gün yemekleri ve bunlara bağlı olarak gelişen mutfak kültürünü analiz etmiştir. Güldemir ve Işık (2011), çalışmalarında Nevşehir mutfak kültürünü günlük öğünler; geçiş dönemlerinde yapılan yiyecekler ve uygulamaları; kutsal günler; neşeli günler; istek/dilek sofraları; kışlık yiyecekler; sofra düzenleri; mutfak araçları; pişirme yöntemleri; servis düzenleri; mutfak mimarisi; içecekler; 
çorbalardan yöresel çarşı yemeklerine kadar yemekler ve tarifleri ekseninde 12 kişi ile görüşme yaparak ve ikincil kaynaklardan yararlanarak analiz etmişlerdir. Sarı (2011), çalışmasında keşkeğin Çankırı'nın Kurşunlu ilçesi mutfak kültüründeki yerini gözlem ve görüşme yöntemiyle inceledikten sonra Kurşunlu'da yaşanan sosyoekonomik dönüşümlerle birlikte keşkeğe yüklenen kimi anlamların değiştiği, keşkeğin yapılış sıklığının azaldığı ve keşkeğin bir şölen yemeği olmaktan çıkıp sıradan/gündelik bir yemeğe dönüştüğü sonucuna ulaşmıştır. Sağır (2012), Tokat mutfağı üzerine yürüttüğü çalışmasında ikincil kaynaklar kullanarak etli yemeklerinden üzüm yaprağını kullanarak yapılan yemeklere, tatlılardan çorbalara kadar çok çeşitli gıdanın sofralarda yer aldığı, pek çok gıda hazırlığında insanların bir araya gelerek toplumsal dayanışmayı sürdürdüğ̈̈; ancak toplumsal değişmelerin yemek kültürünü de etkilediği, özellikle geçmişte sıklıkla yapılan bazı geleneksel eğlence biçimlerinin bugün kaybolduğu, teknolojinin sağladığı imkânların toplum arasındaki birlikteliği en aza indirdiği sonucuna ulaşmıştır. Çölbay ve Sormaz (2015), Konya iline ait yöresel mutfak uygulamalarını incelemek amacıyla yürüttükleri çalışmada yüz yüze görüşme tekniği kullanarak 10 kişiden elde ettikleri bilgileri, yaz ve kış mevsimi ile özel günlerdeki pratikler çerçevesinde derlemişlerdir. Alyakut ve Polat Üzümcü (2017), Kocaeli'nin Kandıra ilçesi Goncaaydın köyünde yaşayan toplam 11 kadın üzerinde yürüttükleri çalışmada Kandıra mutfak kültürünü analiz etmişlerdir. Çalışmada sonucunda Kandıra beslenme kültürünün Manav kültürüyle özdeşleştiği ve bu bağlamda köyde sıklıkla hamur işi yiyecekler ve yöresel otlar pişirildiği, yöresel yemeklerin unutulmaya yüz tuttuğu, gastronomi turizmi açısından uygun olan yörede gastronomik çekiciliği yaşatmak ve gelecek kuşaklara aktarmak için çaba gösterilmediği, halkın gastronomik zenginliğin yaşatılması ve aktarılması konusunda bilinç eksikliğinin olduğu ve yörede farkındalık oluşturmaya yönelik herhangi bir çalışmanın bulunmadığı tespit edilmiştir. Işık vd. (2017), çalışmalarında 50 yaş ve üzeri 11 kişi ile yüz yüze görüşerek Konya'nın Ilgın mutfak kültürü ile ilgili elde ettikleri bilgileri derlemişlerdir. Çalışmada Ilgın yöresinin kışlık ve yazlık öğünleri; doğumdan ölüme kadarki geçiş dönemlerindeki yeme-içme ile ilişkili âdetleri; dilek istek sofraları; dini gün ve bayramlarında tüketilen yiyecek ve içecekler; kışlık besinler; yemekler ve tarifleri sistematik bir şekilde aktarılmıştır. Çakıcı ve Zencir (2018), Afyonkarahisar'ın Şuhut ilçesine bağlı Çakırözü köyünün mutfak kültürünün kaybolmaya yüz tutmuş değerlerinin ortaya çıarılması için 10 kişi ile yarı yapılandırılmış görüşme yöntemi ile bir çalışma gerçekleştirilmişlerdir. Araştırma sonucunda Çakırözü köyü mutfak kültürünün değiştiği ve eskisi kadar ürün çeşitliliği olmadığı ortaya konmuştur.

Çalışmalardan elde edilen bulgular, Türkiye'nin yerel mutfak kültürünün zenginliğini ortaya koymaktadır. Özellikle teknolojide yaşanan değişimlerin yerel mutfak kültürlerinin değişimini olumsuz yönde etkilediği görülmüştür. Tüketici beklenti ve isteklerinin farklılaştığı, yenilik arayışı içerisinde olan turist sayısının arttı̆̆ günümüzde kırsala ve yerel mutfağa yönelik ilgi artmıştır. Ilgaz, bu yönüyle iyi bir konuma sahiptir.

\section{YÖNTEM}

\section{Araştırmanın Evreni ve Örneklemi}

Araştırmanın evreni; Ilgaz ilçesinde doğan ve yaşayan, yöresel yemek yapma konusunda bilgisi olan kadınlardır. Araştırmanın örneklemini ise Ilgaz ilçesinde doğan ve ilçe merkezinde yaşayan 60 yaş ve üstü 11 kadın oluşturmaktadır. 


\section{Araştırma Verilerinin Toplanması}

Araştırma verilerinin toplanmasında görüşme yöntemi kullanılmıştır. Görüşme, nitel araştırmalarda en sık kullanılan veri toplama aracıdır (Yıldırım ve Şimşek, 2008: 119). Görüşme yöntemi; derin bilgi elde edilmesini sağlamaktadır ve yapılandırılmış, yarı yapılandırılmış ve yapılandırılmamış olmak üzere üç biçimde kullanılabilmektedir (Mil, 2007: 3, 8). Bu araştırmada yapılandırılmış görüşme yöntemi kullanılmıştır. Yapılan görüşmelerde katılımcılara yaş, medeni durum, eğitim durumu ve meslek olmak üzere 4 sosyodemografik soru yöneltilirken Ilgaz mutfak kültürüne ilişkin ise 7 soru yöneltilmiştir. Bu sorular şunlardır:

- Sizce Ilgaz'ın gastronomik değerleri nelerdir?

- Ilgaz'da yaygınlik gösteren Ilgaz taş firın konusunda bilgi verebilir misiniz? Bu firmlarda yapilan yemekler nelerdir? Ne siklıkta bu firıları kullanıyorsunuz?

- Yemek yapmayı ne zaman ve nasıl öğrendiniz?

- Genellikle kış öncesi bir yiyecek-içecek hazırlh̆̆ı yapılmaktadır. Sizler, kış öncesi neler yapıyorsunuz?

- Geçmişteki Ilgaz sofra düzeninden kısaca bahsedebilir misiniz?

- Bayram, düğün ve cenazelerdeki yemek kültürünüzün geçmişi ve günümüzdeki durumundan kısaca bahsedebilir misiniz?

- Yeni neslin Ilgaz mutfak kültürüne yaklaşımını nasıl buluyorsunuz?

"Bayram, düğ̈̈n ve cenazelerdeki yemek kültürünüzün geçmişi ve günümüzdeki durumundan kısaca bahsedebilir misiniz?", "Genellikle kış öncesi bir yiyecek-içecek hazırlığı yapılmaktadır. Sizler, kış öncesi neler yapıyorsunuz?" ve "Geçmişteki Ilgaz sofra düzeninden kısaca bahsedebilir misiniz?" soruları Alyakut ve Polat Üzümcü (2017)'nün ve Işık vd. (2017)'nin çalışmalarından yararlanılarak oluşturulmuştur. Diğer araştırma soruları araştırmacı Dağdeviren tarafından hazırlanmıştır. Araştırma, 16.12.2019-30.12.2019 tarihleri arasında katılımcılara uygulanmıştır.

\section{Araştırma Verilerinin Analizi}

Araştırma verilerinin analizinde betimsel analiz yaklaşımından yararlanılmıştır. Bu yaklaşıma göre elde edilen veriler, araştırma sorularının ortaya koyduğu temalara göre düzenlenebileceği gibi görüşme süreçlerinde kullanılan sorular ya da boyutlar dikkate alınarak da sunulabilir. Görüşülen bireylerin görüşlerini çarpıcı bir biçimde yansıtmak amacıyla doğrudan alıntılara sık sık yer verilir. Bu tür analizde amaç, elde edilen bulguları düzenlenmiş ve yorumlanmış bir şekilde okuyucuya sunmaktır (Yıldırım ve Şimşek, 2008: 224). Araştırma sorularına verilen yanıtlar, katılımcılardan izin alındıktan sonra ses kayıt cihazıyla kaydedilmiştir. Ses kayıt cihazına kaydedilen araştırma verileri çözümlenerek metin haline dönüştürülmüştür. Katılımcıların gerçek isimleri gizlenmiş ve K1, K2, K3 vb. şeklinde kodlanmıştır. Elde edilen verilerin sunumunda görüşmede kullanılan sorular dikkate alınmıştır.

\section{BULGULAR}

\section{Katılımcıların Sosyodemografik Özellikleri}

Tablo 1'de görüldüğü gibi katılımcıların en yaşlı olanını 70 yaşındaki iki kişi oluşturmaktadır. Katılımclardan biri, yöresel ürün satıcısı iken diğer katılımcılar, ev hanımıdır. Katılımcılardan biri, herhangi bir eğitim kurumundan mezuniyet değilken diğer katılımcılar, ilkokul mezunudur. Katılımcılardan üçü bekâr, sekizi ise evlidir. 
Tablo 1. Katılımclların Sosyodemografik Özellikleri

\begin{tabular}{ccccc}
\hline Katılımc1 & Yaş & Medeni Durum & Eğitim Durumu & Meslek \\
\hline K1 & 60 & Evli & İkokul & Yöresel Ürün Satıcısı \\
K2 & 63 & Evli & İkokul & Ev Hanımı \\
K3 & 60 & Evli & Ilkokul & Ev Hanımı \\
K4 & 63 & Bekâr & Ilkokul & Ev Hanımı \\
K5 & 68 & Evli & İlkokul & Ev Hanımı \\
K6 & 61 & Evli & İkokul & Ev Hanımı \\
K7 & 65 & Evli & İlkokul & Ev Hanımı \\
K8 & 70 & Evli & Yok & Ev Hanımı \\
K9 & 64 & Evli & Ilkokul & Ev Hanımı \\
K10 & 60 & Bekâr & Ilkokul & Ev Hanımı \\
K11 & 70 & Bekâr & Ilkokul & Ev Hanımı \\
\hline
\end{tabular}

\section{Katılımcıların Ilgaz Mutfak Kültürüne İlișkin Görüșleri}

\section{Sizce Ilgaz'ın Gastronomik Değerleri Nelerdir?}

Tablo 2'de görüldüğü gibi katılımclar, çorba olarak dene çorbasını, oğmaç çorbasını, hamur çorbasını, bulamaç çorbasını, iri tarhana çorbasını, ovalama çorbasını, kabak çorbasını, tarhana çorbasını, sütlü çorbayı, toyga çorbasını, soğuk yarma çorbasını, ekşili çorbayı, pestilli çorbayı, ayranlı köfte çorbasını; yemek olarak keşkeği, güveci, Hacıhasan lahanası ile yapılan sarmayı, etli bamyayı; tatlı olarak kara kabak tatlısını, uğudu, pestili, balı, kavutu, pıhtıyı, sarı̆̆ı burma tatlısını, öküz helvasını, şeker pancarını (közde); hamur işi olarak erişteyi, perişkayı, çizlembeci, damat böreğini, kül çöreğini, tava çöreğini, oklaç ekmeğini, kaydırmayı; içecek olarak ise erik acısını ve yayık ayranını Ilgaz'ın gastronomik değeri olarak ifade etmişlerdir.

Tablo 2. Ilgaz'ın Gastronomik Değerleri

\begin{tabular}{|c|l|}
\hline Katılımc1 & Görüş \\
\hline K1 & $\begin{array}{l}\text { Oğmaç çorbası, keşkek, güveç, pestil, kara kabak tatlısı, uğut, kül çöreği (Unutulmaya yüz } \\
\text { tuttu.), çizlembeç, oklaç ekmeği. }\end{array}$ \\
\hline K2 & Toyga (Sıcak yarma) çorbası, soğuk yarma çorbası, tarhana çorbası, keşkek, güveç. \\
\hline K3 & Keşkek, şeker pancarı (közde), kül çöreği (Unutulmaya yüz tuttu.), yayık ayranı. \\
\hline K4 & $\begin{array}{l}\text { Oğmaç çorbası, bulamaç çorbası, iri tarhana çorbası, dene çorbası, toyga çorbası, ovalama } \\
\text { çorbası, kabak çorbası, keşkek, güveç, etli bamya, kara kabak tatlısı, Hachasan lahanası ile } \\
\text { yapılan sarma, tava çöreği. }\end{array}$ \\
\hline K5 & $\begin{array}{l}\text { Tarhana çorbası, sütlü çorba, oğmaç çorbası, keşkek, perişka, etli bamya, pıhtı, ev yapımı } \\
\text { sucuk ve pastırma (Unutulmaya yüz tuttu.), pestil, erik acısı, güveç, sarığı burma, kara } \\
\text { kabak tatlısı. }\end{array}$ \\
\hline K6 & $\begin{array}{l}\text { Sütlü çorba, tarhana çorbası, keşkek, güveç, etli bamya, Hacıhasan lahanası ile yapılan } \\
\text { sarma, ev yapımı pastırma (Unutulmaya yüz tuttu.), bal, erik acısı. }\end{array}$ \\
\hline K7 & $\begin{array}{l}\text { Dene çorbası, oğmaç çorbası, keşkek, kavut, kaydırma, uğut, Haçhasan lahanası ile yapılan } \\
\text { sarma, erişte, perişka, oklaç ekmeği, kül çöreği (Unutulmaya yüz tuttu.), tava çöreği. }\end{array}$ \\
\hline K8 & $\begin{array}{l}\text { Keşkek, kavut, arpa kavurgası, öküz helvası, Hacıhasan lahanası ile yapılan sarma, } \\
\text { kaydırma, perişka, pıhtı, kül çöreği (Unutulmaya yüz tuttu.), damat böreği, oklaç ekmeği. }\end{array}$ \\
\hline K9 & $\begin{array}{l}\text { Hamur çorbası, oğmaç çorbası, dene çorbası, ayranlı köfte çorbası, sütlü çorba, keşkek, } \\
\text { perişka, güveç, pıhtı, Hacıhasan lahanası ile yapılan sarma. }\end{array}$ \\
\hline K10 & $\begin{array}{l}\text { Oğmaç çorbası, toyga çorbası, ekşili çorba, pestilli çorba, keşkek, Hacıhasan lahanası ile } \\
\text { yapılan sarma, kara kabak tatlısı, kavut, pıhtı, perişka, kül çöreği (Unutulmaya yüz tuttu.), } \\
\text { erik acısı, güveç. }\end{array}$ \\
\hline $\begin{array}{l}\text { Oğmaç çorbası, dene çorbası, tarhana çorbası, sütlü çorba, pestil, perişka, güveç, pihtı, kara } \\
\text { kabak tatlısı, erik acısı, tava çöreği. }\end{array}$ \\
\hline
\end{tabular}


Ayrıca ev yapımı sucuk ve pastırma ile arpa kavurgasını Ilgaz'ın gastronomik değeri olarak ifade etmişlerdir. Araştırma sonucunda ev yapımı sucuk ve pastırma ile kül çöreğinin Ilgaz'ın unutulmaya yüz tutan gastronomik değeri olduğu ortaya çıkmıştır. Katılımcılar, aynı yemeklerin yapılışında Ilgaz ile Çankırı arasında usul farklılıkları olduğunu, Çankırı genelinde keşkek yapılsa da keşkek denince akla Ilgaz'ın geldiğini vurgulamışlardır. Diğer taraftan Hacıhasan lahanası ile yapılan sarmanın Ilgaz'ın doğal koşullarında yetişen lahana nedeniyle lezzetli olduğunu, yayık ayranının Ilgaz'ın doğal koşullarında otlayan ineklerden elde edilen süt nedeniyle farklılık gösterdiğini belirtmişlerdir.

\section{Ilgaz'da Yaygınlık Gösteren Ilgaz Taş Fırını Konusunda Bilgi Verebilir Misiniz? Bu Fırınlarda Yapılan Yemekler Nelerdir? Ne Siklıkta Bu Firınları Kullanıyorsunuz?}

Tablo 3. Ilgaz Taş Fırını Konusundaki Bilgi, Bu Fırınlarda Yapılan Yemekler ve Bu Fırınların Kullanılma Sıklığı

\begin{tabular}{|c|c|}
\hline Katılımcı & Görüş \\
\hline K1 & $\begin{array}{l}\text { Ben kendimi bildim bileli var. Apartmanda bir bölüm sırf bunun için ayrılır. } \\
\text { Ramazan ayında her gün güveç ve keşkek pişirilir. Fırınların yapımını özel ustalar } \\
\text { ve çok yaşlı kişiler bilir. }\end{array}$ \\
\hline K2 & $\begin{array}{l}\text { Tarihini bilmiyorum, ama kendimi bildim bileli taş fırınlar var. Genellikle keşkek } \\
\text { yaparken kullanıyoruz. Bazen, bazlama ve ekmek de yapıyoruz. }\end{array}$ \\
\hline K3 & $\begin{array}{l}\text { Fırın köyde yaşadığımız zamanda da vardı. Önceden köyler çok büyük ve bir tane } \\
\text { fırın vardı, herkes kendi odununu götürürdü. Şu an neredeyse, her apartmanda } \\
\text { fırın var. Genellikle ekmek, çörek, keşkek yaparken kullanılır. }\end{array}$ \\
\hline K4 & $\begin{array}{l}\text { Ben doğdum doğalı fırınlar var. Önceden Ilgaz'da her evin önünde vardı. Benim } \\
\text { köyümde de bir tane fırın vardı, o da artık yıkıldı. Genellikle fırınlarda etli bamya, } \\
\text { barbunya, dolma, keşkek, kuru fasulye yemeği ile ekmek yapılır. }\end{array}$ \\
\hline K5 & $\begin{array}{l}\text { Fırınlar çok eskiden beridir var. Ramazan ayında her gün yakılır. Normal günlerde } \\
\text { ve misafir geldiğinde ise isteğe bağlı olarak yakılır. Keşkek, güveç, kara kabak, } \\
\text { kuru fasulye gibi yemekler pişirilir. }\end{array}$ \\
\hline K6 & $\begin{array}{l}\text { Fırınların geçmişi çok eski. Kendi köyümüzde de vardı. Şimdi de sitede } 70 \text { aile } \\
\text { 2'şer kişi olarak odunumuzu alarak sırayla fırınımızı yakıyoruz. Keşkek, güveç, } \\
\text { lahana sarması, karnıyarık gibi yemekler ile ekmek yaparken kullanıyoruz. }\end{array}$ \\
\hline K7 & $\begin{array}{l}\text { Tam tarihini bilmem; ama bu fırınlar, kendimi bildim bileli var. Keşkek, ekmek, } \\
\text { güveç, kabak gibi yemekler pişiriyoruz. Ramazan ayında her gün yakıyoruz. } \\
\text { Eskisi kadar çok kullanılmıyor aslında. }\end{array}$ \\
\hline K8 & $\begin{array}{l}\text { Çok eskilerden bu tarafa var. Eskiden ocaklar yokken herkes orda yemek pişirirdi. } \\
\text { Ramazan ayında her gün yakarız. Şimdi ise canımız istediği zaman komşularla bir } \\
\text { araya gelip yakıyoruz. }\end{array}$ \\
\hline K9 & $\begin{array}{l}\text { Fırınlar senelerdir var. Komşular bir araya gelince yakıyoruz. Ramazan ayında ise } \\
\text { sürekli yanar. Genellikle fırınlarda çorba ile güveç, keşkek, sarma, nohut, kuru } \\
\text { fasulye yemeği yapılır. }\end{array}$ \\
\hline K10 & $\begin{array}{l}\text { Çocukluğumda da vardı. Her türlü yemek pişirilebilir bu fırınlarda; ama genellikle } \\
\text { keşkek, sarma, kuru fasulye, güveç pişirilir. Şimdilerde sadece Ramazan ayında } \\
\text { yakıyoruz. }\end{array}$ \\
\hline K11 & $\begin{array}{l}\text { Çok eskilere dayanan bir tarihi var. Genellikle çorba ve çörek yaparken; keşkek, } \\
\text { güveç, kuru fasulye yemeği yaparken kullanıyoruz. Ramazan ayında her gün } \\
\text { yanar. Normalde ise komşular toplanıp istediğimiz zaman yakıyoruz. }\end{array}$ \\
\hline
\end{tabular}


Tablo 3’te görüldüğü gibi katılımcıların tümü, taş fırınların oluşturulma tarihini tam olarak bilmediklerini; ancak çocukluklarından bu yana bu fırınların olduğunu ifade etmişlerdir. Ayrıca katılımcılar, Ramazan ayı başta olmak üzere taş fırınlarının hâlâ aktif şekilde kullanıldığını ve özellikle keşkek ve güveç olmak üzere birçok yemeği bu fırınlarda pişirdiklerini ifade etmişlerdir.

\section{Yemek Yapmayı Ne Zaman ve Nasıl Öğrendiniz?}

Tablo 4'te görüldüğü gibi katılımcıların çoğu, 10 yaşın üstünde yemek yapmaya başladıklarını ve istekli bir şekilde yemek yapmayı öğrendiklerini ifade etmişlerdir.

Tablo 4. Yemek Yapmayı Öğrenme Zamanı ve Nasıl Öğrenildiği

\begin{tabular}{|c|l|}
\hline Katılımcı & Görüş \\
\hline K1 & $\begin{array}{l}\text { Hem babamdan hem annemden öğrendim. Babam aşçıbaşıydı. Ondan kalma bir yetenek } \\
\text { var. Annem normal günlerde, babam ise özel günlerde yapardı. İstekli ve severek } \\
\text { başladım bu işe. İlgim vardı, hâlâ da var. 8-9 yaşımda başladım. }\end{array}$ \\
\hline K2 & 12 yaşında annemden öğrendim. İstekliydim. Şimdide istekli olarak yapıyorum. \\
\hline K3 & 15-16 yaşlarında annemin zoruyla öğrendim. Şimdide mecbur olduğum için yapıyorum. \\
\hline K4 & 16-17 yaşlarında evlendikten sonra kayınvalidemden öğrendim. Severek yapıyorum. \\
\hline K5 & $\begin{array}{l}\text { Annem ben } 6 \text { yaşındayken vefat ettiği için büyük annemden 8-9 yaşlarındayken } \\
\text { ögrendim. Severek yapıyorum. }\end{array}$ \\
\hline K6 & $\begin{array}{l}\text { 8-9 yaşlarında annemden öğrendim. Ev işi yapmayı da sevdiğim için yemek yapmayı da } \\
\text { öyle öğrendim. }\end{array}$ \\
\hline K7 & 8-9 yaşlarında annemden ve isteyerek öğrendim. İlk yaptı̆̆ım şey, ekmek hamuruydu. \\
\hline K8 & 10-12 yaşlarında annemden öğrendim. Yemek yapmaya ilgim vardı. İsteyerek öğrendim. \\
\hline K9 & 10-11 yaşlarında, annemden öğrendim yemek yapmayı. Severek, isteyerek öğrendim. \\
\hline K10 & Merakım ve ilgim vardı. Kimsenin zorlamasıla öğrenmedim. 15-16 yaşlarındaydım. \\
\hline K11 & 12-13 yaşlarında annemden öğrendim. Mecbur olduğum için öğrendim. \\
\hline
\end{tabular}

4. Genellikle Kış Öncesi Bir Yiyecek-İçecek Hazırlı̆̆ı Yapılmaktadır. Sizler, Kış Öncesi Neler Yapiyorsunuz?

Tablo 5. Kış Öncesi Yapılan Yiyecek-İçecek Hazırlığı

\begin{tabular}{|c|c|}
\hline Katılımcı & Görüş \\
\hline K1 & $\begin{array}{l}\text { Yeşil fasulye, erik, elma, armut kuruturuz. Genellikle salatalık, fasulye, lahana turşusu yaparız. } \\
\text { Tarhana, makarna, perişka, salça, erişte yaparız. Ayrıca kuşburnu, kızılcık gibi marmelatlar yaparız. }\end{array}$ \\
\hline K2 & Yeşil fasulye, erik, elma, kuşburnu kuruturuz. \\
\hline K3 & Perişka yaparız. Fasulye ve elma kuruturuz. \\
\hline K4 & $\begin{array}{l}\text { Perişka, menemenlik yaparız. Domates, biber, patlıcan kuruturuz. Erik, dağ çileği reçeli yaparız. } \\
\text { Genelde lahana ve salatalık turşusu yaparız. }\end{array}$ \\
\hline K5 & $\begin{array}{l}\text { Fasulye ve elma kuruturuz. Konserveler (menemenlikler, fasulye), erişte, kuşburnu marmelatı, erik } \\
\text { ve dağ çileği reçeli, erik acısı, turşu yaparız. Önceden et kuruturduk. }\end{array}$ \\
\hline K6 & Tarhana, perişka, turşu yaparız. Önceden et, elma, erik gibi şeyleri kuruturduk. Pastırma yapardık. \\
\hline K7 & $\begin{array}{l}\text { Karışık, salatalık, fasulye ve lahana turşusu ile menemenlik, erişte, keşkeklik buğday, perişka, erik } \\
\text { acısı, reçeller yaparız. }\end{array}$ \\
\hline K8 & $\begin{array}{l}\text { Elma, ayva gibi meyveleri kurutuyoruz. Erik acısı, kuşburnu marmelatı, reçel (erik, kızılcık gibi), } \\
\text { keşkeklik buğday, turşu, erişte, perişka, tarhana yapıyoruz. }\end{array}$ \\
\hline K9 & $\begin{array}{l}\text { Menemenlik yaparız. Patlıcan, biber, fasulye, kabak kuruturuz. Tarhana, makarna, perişka, erişte, } \\
\text { reçeller, erik acısı yaparız. }\end{array}$ \\
\hline K10 & $\begin{array}{l}\text { Kuşburnu marmelatı, reçeller (dağ çileği, erik vb.) yaparız. Fasulye, elma, erik kuruturuz. Tarhana, } \\
\text { erişte, elma pekmezi, erik acısı, turşu yaparız. }\end{array}$ \\
\hline K11 & $\begin{array}{l}\text { Menemenlik, perişka, iri tarhana, erik acısı yaparız. Elma ve fasulye kurutur, başta lahana olmak üzere } \\
\text { turşu yaparız. }\end{array}$ \\
\hline
\end{tabular}


Tablo 5'te görüldüğü gibi katılımcıların çoğu, kış öncesi fasulye, elma, erik gibi gıdaları kuruttuklarını; kış öncesi ağırlıklı olarak turşu, reçel, tarhana, erişte ve perişka yaptıklarını belirtmişlerdir. Ayrıca katılımcılar, kış öncesi gıda hazırlarken dayanışma içinde hareket ettiklerini vurgulamışlardır.

\section{Geçmişteki Ilgaz Sofra Düzeninden Kısaca Bahsedebilir Misiniz?}

Tablo 6' da görüldüğ̈̈ gibi katılımcıların tümü; yer sofralarında yemeklerini yediklerini, K4 hariç, tüm katılımcılar ise tek bir tabakta ve tahta kaşıklarla yemeklerini yediklerini ifade etmişlerdir. Kadın ve erkeklerin aynı sofralarda bulunduğu zamanlarda kadınların yaşmak taktığı ifade edilmiştir.

Tablo 6. Geçmişte Ilgaz Sofra Düzeni

\begin{tabular}{|c|l|}
\hline Katılımcı & Görüş̧ \\
\hline K1 & $\begin{array}{l}\text { Yer sofrasında yerdik. Kadınlar ve erkekler ayrı odalarda yerdi. Yemekleri, tek } \\
\text { tabaktan ve tahta kaşıklarla yerdik. Önceden kadınlar, erkeklerin yanında } \\
\text { yaşmak yaparlardı, yemek yemezlerdi. }\end{array}$ \\
\hline K2 & $\begin{array}{l}\text { Köyde yemekler tepsiye konulup, yerde tek tabakta, tahta kaşıklarla yenirdi. } \\
\text { Artık herkes tabakta yiyor. }\end{array}$ \\
\hline K3 & $\begin{array}{l}\text { Eskiden kadınlar ayrı, erkekler ayrı yer sofralarında yemeklerini yerdi. } \\
\text { Yemekler, tek sahanda ve tahta kaşıklarla yenirdi. }\end{array}$ \\
\hline K4 & $\begin{array}{l}\text { Eskiden artan yemeklere çok kızarlardı. Yer sofrasında yerdik ve herkes kendi } \\
\text { sahanındaki yemeği yerdi. Tahta kaşılarla yemeklerimizi yemezdik. }\end{array}$ \\
\hline K5 & $\begin{array}{l}\text { Yemekleri yer sofrasında tek tabaktan, tahta kaşıkla, lengerlerle koyup yerdik. } \\
\text { Daha sonra ayrı tabaklarda yenmeye başladı. }\end{array}$ \\
\hline K6 & $\begin{array}{l}\text { Yemekleri yer sofrasında, tek tabaktan ve tahta kaşılarla yerdik. Köye gelen } \\
\text { misafire kesinlikle sofra kurulurdu. }\end{array}$ \\
\hline K7 & $\begin{array}{l}\text { Çok eskiden yemeklerimizi yerde, tek tabaktan ve tahta kaşıklarla yerdik. Her } \\
\text { yemek, kendi tabağında sofraya konurdu. }\end{array}$ \\
\hline K8 & Yemekleri yerde tek tabaktan, tahta kaşıklarla yerdik. \\
\hline K9 & $\begin{array}{l}\text { Yemekleri yer sofrasında tek tabaktan ve tahta kaşıklarla yerdik. Kalabalık aile } \\
\text { olduğumuz için kadınlar ayrı yerde, erkekler ayrı yerde yemeklerini yerdi. }\end{array}$ \\
\hline K10 & $\begin{array}{l}\text { Ailemizde az kişi olduğu için yemekleri hepimiz tek tabaktan, yerde yiyorduk. } \\
\text { Tahta kaşık kullanırdık. }\end{array}$ \\
\hline K11 & $\begin{array}{l}\text { Yemekleri, yerde tek tabaktan, tahta kaşıklarla yiyorduk. Bu gelenek uzun süre } \\
\text { devam etse de artık devam etmiyor. }\end{array}$ \\
\hline
\end{tabular}

\section{Bayram, Düğün ve Cenazelerdeki Yemek Kültürünüzün Geçmişi ve Günümüzdeki Durumundan Kisaca Bahsedebilir Misiniz?}

Tablo 7'de görüldüğgu gibi katılımcıların çoğu, bayramlarda geleneksel yemek kültürünün devam ettiği görüşünde olmasına karşın düğün ve cenazelerde geleneksel yemek kültürünün devam etmediği görüşündedir. 
Tablo 7. Bayram, Dügün ve Cenazelerdeki Yemek Kültürünün Geçmişi ve Günümüzdeki Durumu

\begin{tabular}{|c|c|}
\hline Katılımcı & Görüss \\
\hline K1 & $\begin{array}{l}\text { Kurban Bayramı'nda kurban kesildikten sonra karaciğer pişirilir, komşulara ikram } \\
\text { edilirdi. Bu gelenek hâlâ devam ediyor. Düğülerde kazanlar kurulur; etler, pilavlar, } \\
\text { çorbalar, helvalar yapılırdı. Şu anda bu gelenek kısmen devam ediyor. Cenaze olduğu } \\
\text { zaman komşular, } 1 \text { hafta cenaze evine yemekler yapıp getirirdi. Şimdi maalesef bu } \\
\text { gelenek devam etmiyor. }\end{array}$ \\
\hline K2 & $\begin{array}{l}\text { Bayramlarda baklava ve sütlaç yapılır, Kurban Bayramı'nda et, ikram edilirdi. } \\
\text { Dügünlerde pilav, et, sütlü çorba, helva yapılırdı. Şimdi de bu gelenekler devam } \\
\text { ediyor. Cenazelerde, yakın çevre } 3 \text { kap yemek, } 3 \text { ekmek getirirdi. Şimdi ise bu gelenek } \\
\text { devam etmiyor. Cenazenin ilk günü yemek pişiyor ve odada veriliyor. }\end{array}$ \\
\hline K3 & $\begin{array}{l}\text { Bayram sabahı, erkekler bir evde yemek yer ve bayramlaşırdi. Şimdi ise Ramazan } \\
\text { ayında, } 30 \text { gün boyunca köy meydanında caminin yanındaki köy odasında yemek } \\
\text { veriliyor. Dügüünlerde, düğ̈n sahibi yemek verirdi. Cenazelerde, yakın çevre, kendi } \\
\text { evlerinden } 1 \text { hafta yemek yaparak getirirdi. Şimdi; pide, ayran ikram ediliyor. }\end{array}$ \\
\hline K4 & $\begin{array}{l}\text { Bayramlarda; ev baklavası, kadayıf, kesme börek, sütlaç yapılırdı. Şimdi ise hazır } \\
\text { baklava çıtı. Dü̆üünlerde, önceden ince ekmek ve ayran ikram edilirdi. Durumu iyi } \\
\text { olan aileler; güveç, etli bamya, sarma vb. yemekler yapıp ikram ederdi. Cenaze evine, } \\
\text { yakın çevre tereyağlı ekmek, bazlamaç ve yemek yapıp getirirdi. Şimdi ise aşçının } \\
\text { yaptığı yemek veriliyor. }\end{array}$ \\
\hline K5 & $\begin{array}{l}\text { Bayramlarda ve dügünlerde ince ekmek, keşkek, yaprak sarması, etli bamya, sütlü } \\
\text { çorba, baklava yapardık. Şimdi de bu gelenek devam ediyor. Cenaze evine, her evden } \\
\text { yemek gelirdi. Bu gelenek unutulmaya yüz tutsa da biz hâlâ bu geleneği devam } \\
\text { ettiriyoruz. }\end{array}$ \\
\hline K6 & $\begin{array}{l}\text { Bayramlarda, erkeklerin katıldığ köy odalarına her evden bir sofra çıkardı. Şimdi bu } \\
\text { gelenek devam etmiyor. Düğünlerde, sütlü çorba, pilav, sarma, keşkek, tatlı yapardık. } \\
\text { Şimdi ise aşçının yaptığı yemeği ikram ediyoruz. Cenazelerde, önceden } 1 \text { hafta } \\
\text { komşular yemek getirirdi. Şimdi ise bu gelenek devam etmiyor. }\end{array}$ \\
\hline K7 & $\begin{array}{l}\text { Bayramlarda, yemekler yapılırdı; fasulye yemeği, pilav, tatlı, turşu, yaprak dolması ve } \\
\text { kelem dolması kesinlikle yapılırdı. Şimdi de bu geleneği devam ettiriyoruz. } \\
\text { Düğünlerde, çorba, keşkek, dolma, pilav, kaydırma yapılırdı. Şu anda bu geleneği } \\
\text { devam ettiren kimse yok. Cenazelerde, komşular } 1 \text { hafta yemek getirirdi. Şimdi; pide, } \\
\text { ayran ve hazır yemek ikram ediliyor. }\end{array}$ \\
\hline K8 & $\begin{array}{l}\text { Düğünlerde, çorba, keşkek, dolma, pilav, kaydırma yapılırdı. Şimdi yapan kimse yok. } \\
\text { Bayramlarda, yaprak sarması, sütlü çorba, baklava ve tatlı konulurdu. Şimdi bu } \\
\text { gelenek devam ediyor. Cenazelerde, } 1 \text { hafta komşular yemek yapıp getirirdi. } \\
\text { Günümüzde cenaze evinde pide ve ayran ikram ediliyor. }\end{array}$ \\
\hline K9 & $\begin{array}{l}\text { Bayramlarda, tatlı, börek, sarma verilirdi. Bu gelenek hâlâ devam ediyor. Dü̆g̈ünlerde, } \\
\text { keşkek, sütlü çorba, tahin helvası yapardık. Şimdi ise aşçı tutulup köylüye yemek } \\
\text { veriliyor. Cenazelerde, komşu evlerden yemek yapılır, götürülürdü. } 7 \text { gün yemek } \\
\text { giderdi cenaze evine. Şimdi cenaze günü pide ve ayran ikram ediliyor. }\end{array}$ \\
\hline K10 & $\begin{array}{l}\text { Bayramlarda sütlü çorba, tatlı, keşkek gibi yemekler yapılırdı. Bu kültür hâlâ devam } \\
\text { ettiriliyor. Dügüulerde, toyga çorbası, ekşili çorba, pestilli çorba, keşkek, pilav ikram } \\
\text { ediliyordu. Şimdilerde lokantalarla anlaşı köydeki herkese yemek veriliyor. } \\
\text { Cenazelerde ise komşular, } 7 \text { gün yemek yapıp getirirlerdi. Şimdi pide ve ayran } \\
\text { veriliyor. }\end{array}$ \\
\hline K11 & $\begin{array}{l}\text { Bayramlarda özellikle keşkek, tatlı yapılırdı. Şimdi baklava, börek veriliyor. } \\
\text { Düğünlerde ise sütlü çorba, keşkek, etli yemekler, tatlı, pilav yapardık. Şimdi aşçı } \\
\text { tutulup yemek veriliyor. Cenazelerde, komşular } 1 \text { hafta evlerinden yemek getirirdi. } \\
\text { Şimdi cenaze evi yemek veriyor. }\end{array}$ \\
\hline
\end{tabular}




\section{Yeni Neslin Ilgaz Mutfak Kültürüne Yaklaşımını Nasıl Buluyorsunuz?}

Tablo 8'de görüldügü gibi katılımcıların çoğu, yeni neslin Ilgaz mutfak kültürüne karşı ilgili ve bu kültürü devam ettirme konusunda gayretli olduklarını ve kül çöreği, keşkek, perişka, tarhana gibi yöresel gıdaları ürettiklerini ifade etmişlerdir.

Tablo 8. Yeni Neslin Ilgaz Mutfak Kültürüne Yaklaşımı

\begin{tabular}{|c|l|}
\hline Katılımc1 & Görüş \\
\hline K1 & $\begin{array}{l}\text { Çevremdeki kişiler, biraz ilgisiz; ama benim çocuklarım oldukça ilgili. Kül } \\
\text { çöreğini, keşkeği seviyorlar ve yapıyorlar. Keşkeği, bazen kırmızı etli bazen } \\
\text { tavuk etli yaparlar. Bazlamayı, ince ekmeği, baklavayı yaparken severek yardım } \\
\text { ediyorlar. }\end{array}$ \\
\hline K2 & $\begin{array}{l}\text { Çocuklarım ilgililer. Örneğin; kül çöreğini ve oklaç ekmeğini yapıyorlar. Yöresel } \\
\text { yemekleri seviyorlar ve yapıyorlar. }\end{array}$ \\
\hline K3 & Yöresel yemeklere pek ilgi duymuyorlar. Mutfağa ilgileri yok. \\
\hline K4 & Yeni neslin Ilgaz mutfak kültürüne ilgisi var ve devam ettirmek istiyorlar. \\
\hline K5 & $\begin{array}{l}\text { Yöresel yemekleri seviyorlar. İlgileri ve merakları var. Kültürü devam ettirmeye } \\
\text { çalışyorlar. }\end{array}$ \\
\hline K6 & Merakları yok ve ilgisizler. \\
\hline K7 & $\begin{array}{l}\text { İlgileri ve merakları var. Keşkek ve oğmaç çorbasını yapıyorlar; fakat ekmek ya } \\
\text { da çörek türü yiyecekleri yapmaya pek sıcak bakmıyorlar. }\end{array}$ \\
\hline K8 & $\begin{array}{l}\text { İgileri var. Genel olarak yaptığımız tüm yemekleri biliyor ve kendi çocuklarına } \\
\text { da yapıyorlar. }\end{array}$ \\
\hline K9 & $\begin{array}{l}\text { Bana göre yeni nesil, olumlu yaklaşıor yöresel yemeklere. Meraklı, ilgili ve } \\
\text { öğrenmeye istekliler. Perişka, tarhana vb. yapıyorlar. }\end{array}$ \\
\hline K10 & $\begin{array}{l}\text { Eski yemekleri severek yiyorlar; ama yapmaya pek yanaşmıyorlar. Bizim } \\
\text { yemekleri yapmak, onlara zor geliyor. }\end{array}$ \\
\hline K11 & $\begin{array}{l}\text { Merakları ve ilgileri var. Kültürü devam ettirmeye çalışıyorlar. Sütlü çorba, } \\
\text { güveç vb. yaparlar. }\end{array}$ \\
\hline
\end{tabular}

Elde edilen bulgular, Ilgaz'da yapılan besinlerin genel olarak Çankırı'dakiler ile benzerlik gösterse de gerek usul gerekse pestilli çorba, damat böreği, kül çöreği, erik acısı, öküz helvası gibi ürünlerle farklılaştığını göstermiştir. Bulgular, Çakıcı ve Zencir (2018: 294)'in çok küçük farklılıklar olsa da Çakırözü köyü yemek kültürünün Afyonkarahisar yemek kültürüne büyük ölçüde benzerlik taşıdığı bulgusu ile uyumludur. Çalışma, yaşanan değişimle birlikte özel günlerdeki yemek kültürünün değişim gösterdiğini ortaya koymuştur. Bulgular, Sağır (2012)'ın ve Çakıcı ve Zencir (2018: 294)'in çalışma verileriyle benzerlik göstermektedir. Ayrıca çalışma, gıda hazırlıklarında dayanışmanın hâlâ devam ettiğini göstermiştir. Bulgular, Sağır (2012)’ın çalışma verileriyle örtüşmektedir.

\section{SONUÇ VE ÖNERILER}

Araştırma sonucunda katılımcların, çorba olarak dene çorbasını, oğmaç çorbasını, hamur çorbasını, bulamaç çorbasını, iri tarhana çorbasını, ovalama çorbasını, kabak çorbasını, tarhana çorbasını, sütlü çorbayı, toyga çorbasını, soğuk yarma çorbasını, ekşili çorbayı, pestilli çorbayı, ayranlı köfte çorbasını; yemek olarak keşkeği, güveci, Hacıhasan lahanası ile yapılan sarmayı, etli bamyayı; tatlı olarak kara kabak tatlısını, uğudu, pestili, balı, kavutu, pıhtıyı, sarığı burma 
tatlısını, öküz helvasını, şeker pancarını (közde); hamur işi olarak erişteyi, perişkayı, çizlembeci, damat böreğini, kül çöreğini, tava çöreğini, oklaç ekmeğini, kaydırmayı; içecek olarak ise erik acısını ve yayık ayranını Ilgaz gastronomik değeri olarak ifade ettikleri, ev yapımı sucuk ve pastırma ile arpa kavurgasını da Ilgaz gastronomik değeri olarak ifade ettikleri görülmüştür. Diğer taraftan ev yapımı sucuk ve pastırma ile kül çöreğinin Ilgaz'ın unutulmaya yüz tutan gastronomik değeri olduğu bulgusuna ulaşılmıştır. Ilgaz taş fırınlarının tarihinin tam olarak bilinmediği, özellikle Ramazan aylarında taş fırınlarının aktif olarak kullanıldığı ortaya çıkmıştır. İlçede uzun bir süredir varlığını sürdüren ve yeni yapılan binalarda da kendisine bir yer ayrılan taş fırınlarının toplumsal işbirliğini ve dayanışmayı sağladığı tespit edilmiştir. Katılımcıların çoğunun yemek yapmayı 10 yaşın üstünde iken öğrendiği ve isteyerek yemek yapmaya başladıkları bulgusuna ulaşılmıştır. Katılımcıların kış öncesi çeşitli gıdaları kuruttukları, turşu ve yoğun olarak tarhana, erişte ve perişka yaptıkları ortaya çıkmıştır. Araştırma sonucunda katılımcıların tümünün geçmişte yer sofralarında yemeklerini yedikleri, K4 dişındaki tüm katılımcıların tek bir tabakta ve tahta kaşıklarla yemeklerini yedikleri belirlenmiştir. Ayrıca katılımcıların çoğunun bayramlarda geleneksel yemek kültürünün devam ettiği görüşünde olduğu, buna karşın düğün ve cenazelerde ise geleneksel yemek kültürünün devam etmediği görüşünde olduğu bulgusuna ulaşılmıştır. Ayrıca araştırma sonucunda katılımcıların çoğu tarafından yeni neslin Ilgaz mutfak kültürüne karşı ilgili ve bu kültürü devam ettirme konusunda gayretli olduğu görüşü ortaya konmuştur.

Araştırma sonucunda elde edilen bulgular ve Ilgaz ilçesinin gastronomi turizminde öne çıkması doğrultusunda planlamacılar ve karar vericiler için şu öneriler geliştirilmiştir:

- Belediye ve kaymakamlığın da katkılarıyla şehir merkezi başta olmak üzere ilçede yöresel gıda ürünleri satış noktaları oluşturulmalıdır.

- İşletmeler, Ilgaz yiyecek-içeceklerini menülerine daha fazla koymalıdırlar.

- 60 yaş ve üstü sinırlı sayıda kadınla görüşülerek gerçekleştirilen araştırma bulgularını genişletmek için daha fazla sayıda örneklem üzerinde bir araştırma yürütülmeli ve elde edilen bulgular doğrultusunda tarifler, besin değerleri ve sofra kültürünü içeren bir "Ilgaz Mutfağı" kitabı hazırlanmalıdır.

- İlçenin mutfak kültürü, nitelikli gastronomi broşürleri ve internet sayfaları ile tanıtılmalıdır. Bu broşürlerde ve internet sayfalarında özellikle taş fırınların görsellerinin de kullanımı sağlanmalıdır.

- Şanlıer (2005: 226)'in de ifade ettiği gibi çeşitli yemek yarışmaları düzenlenerek yemeklerin aslını kaybetmeden sunumlarının yapılması ve tanıtımı yapılmalıdır.

- İlçede keşkek ve tarhana festivali gibi çeşitli gastronomi festivalleri düzenlenmelidir.

- İlçede özellikle bakır ve ağaçtan mutfak malzemelerinin ve ilçeye özgü değerlerin bulunduğu sofra bezlerinin sergilendiği bir kültür evi oluşturulmalıdır.

- Ilgaz Turizm ve Otelcilik Yüksekokulu, Ilgaz Emel-Oktay Türkoğlu Turizm ve Otelcilik Meslek Lisesi, Halk Eğitim Merkezi işbirliğiyle yerel halkın Ilgaz mutfak kültürü konusunda bilgi düzeylerinin artırılması ve Ilgaz yöresel ürünlerinin yapımını öğrenmesi sağlanmalıdır.

- Ilgaz'da gastronomi turizmi, başta kış turizmi olmak üzere yayla ve kültür turizmi gibi diğer turizm türleri ile bütünleştirilmelidir.

\section{KAYNAKÇA}

Alyakut, Ö. ve Polat Üzümcü, T. (2017). Gastronomi Turizmi Bağlamında Kandıra Beslenme Kültürü ve Unutulmaya Yüz Tutmuş Lezzetleri: Goncaaydın Köyü Örneği, IV. Uluslararası Çoban Mustafa Paşa ve Kocaeli Tarihi Kültürü Sempozyumu, 24-26 Mart 2017. Kocaeli. ss: 1837-1861. 
Artun, E. (2001). Adana'da, Törenlere, Adaklara, Özel Günlere Ait İnançlar, Pratikler ve Bunlara Bağlı Mutfak Kültürü. Millî Folklor, 49, 27-37.

Balcı, S., Dağlar, H. ve Gümüşoğlu, Z. (2005). Geçmişten Bugüne Çankırı'da Sofra Adabı ve Yemek Kültürü, Çankırı Valiliği III. Çankırı Kültürü Bilgi Şöleni Bildirileri: Geçmişten Geleceğe Çankırı, 28-29 Eylül 2005. Çankırı. ss: 81-91.

Çakıcı, H. H. ve Zencir, E. (2018). Unutulmaya Yüz Tutmuş Mutfak Kültürleri: Çakırözü Köyü Örneği. Journal of Tourism and Gastronomy Studies, 6(Special issue3), 285-297.

Çakırsipahi, S. (2002). Ilgaz. Ankara: Güner Matbaacılık Ltd. Şti.

Çevik, N. $\quad$ K. $\quad$ (2004). Türk Mutfak Kültürü. http://turkoloji.cu.edu.tr/HALKBILIM/halkbilim_ana.php [Erişim Tarihi: 19.03.2020].

Çölbay, Ş. ve Sormaz, Ü. (2015). Konya'da Geçiş Dönemlerinde Yapılan Yöresel Mutfak Uygulamaları. Uluslararası Türkçe Edebiyat Kültür Ĕ̆itim Dergisi, 4(4), 1729-1736.

Deniz, T. ve Atışman, E. (2017). Kayseri İlinin Gastronomi Turizmine Yönelik Bir SWOT Analizi Çalışması, Türk Turizm Araştırmaları Dergisi, 1(3), 56-65.

Dilek, S. and Keskingöz, H. (2016). SWOT Analysis of Safranbolu City in Terms of Tourism. International Journal of Research in Business and Social Science, 5(1), 54-64.

Durlu Özkaya, F. ve Cömert, M. (2017). Türk Mutfağında Yolculuk. (1. Baskı), Ankara: Detay Yayıncilık.

Güldemir, O. ve Işık, N. (2011). Nevşehir Mutfak Kültürü ve Yemekleri, 1. Uluslararası Nevşehir Tarih ve Kültür Sempozyumu, Nevşehir Üniversitesi, 16-19 Kasım 2011. Nevşehir. ss: 151-176.

Güler, S. (2010). Türk Mutfak Kültürü ve Yeme İçme Alışkanlıkları. Dumlupınar Üniversitesi Sosyal Bilimler Dergisi, 26(1), 24-30.

Işık, N., Kılıçarslan, A., Derin, D. Ö. ve Barı, N. (2017). Ilgın Mutfak Kültürü ve Yemekleri, Selçuk Üniversitesi Sosyal Bilimler Enstitüsü Dergisi, (38), 86-94.

Jalis, M. H., Che, D. and Markwell, K. (2014). Utilising Local Cuisine to Market Malaysia as a Tourist Destination. Procedia-Social and Behavioral Sciences, 144, 102-110.

Karim, S. A. and Chi, C. G. Q. (2010). Culinary Tourism as a Destination Attraction: An Empirical Examination of Destinations' Food Image, Journal of Hospitality Marketing \& Management, 19(6), 531-555.

Kut, G. (2002). Türklerde Kemek Kültürü. http://docs.neu.edu.tr/library/nadir_eserler_el_yazmalari/Ansiklopedi/T\%C3\%9CRKLER\%20A NS\%C4\%B0KLOPED\%C4\%B0S\%C4\%B0/T4/0940-G\%C3\%BCnay\%20Kut_4.cilt.pdf [Erişim Tarihi: 29.03.2020].

López-Guzmán, T. and Sánchez-Cañizares, S. (2012). Gastronomy, Tourism and Destination Differentiation: A Case Study in Spain. Review of Economics \& Finance, 1, 63-72.

Mil, B. (2007). Nitel Araştırma Tekniği Olarak Görüşme, (Editör) Yüksel, A., Mil, B. ve Bilim, Y.: Nitel Araştırma: Neden, Nasıl, Niçin içinde (ss. 3-26) Ankara: Detay Yayıncılık.

Okumus, B., Okumus, F. and McKercher, B. (2007). Incorporating Local and International Cuisines in the Marketing of Tourism Destinations: The Cases of Hong Kong and Turkey. Tourism Management, 28, 253-261. 
Özgen, I. (2017). Uluslararası Gastronomiye Genel Bakış, (Editör) Sarışık, M.: Uluslararası Gastronomi (Temel Özellikler-Örnek Menüler ve Reçeteler) içinde (ss. 1-29), Ankara: Detay Yayınc1lı.

Sağır, A. (2012). Bir Yemek Sosyolojisi Denemesi Örneği Olarak Tokat Mutfağı. Electronic Turkish Studies, 7(4), 2675-2695.

Sarı, E. (2011). Kurşunlu Mutfak Kültüründe Keşkek: Geçmişi, Bugünü ve Yarını. Milli Folklor, 23(90), 185-194.

Sürücüoğlu, M. S. ve Özçelik, A. Ö. (2007). Türk Mutfak ve Beslenme Kültürünün Tarihsel Gelişimi, 38. Uluslararası Asya ve Kuzey Afrika Çalışmaları Kongresi, Atatürk Kültür, Dil ve Tarih Yüksek Kurumu 10-15 Eylül 2007. Ankara. ss: 1289-1310.

Şahin, S. Z. (2019). Çorum Mutfağının Gastronomi Turizmi Potansiyeli. Journal of Tourism and Gastronomy Studies, 7(4), 2550-2565.

Şanlıer, N. (2005). Yerli ve Yabancı Turistlerin Türk Mutfağı Hakkındaki Görüşleri. Gazi Üniversitesi Gazi Eğitim Fakültesi Dergisi, 25(1), 213-227.

Talas, M. (2005). Tarihi Süreçte Türk Beslenme Kültürü ve Mehmet Eröz'e Göre Türk Yemekleri. Selçuk Üniversitesi Türkiyat Araştırmaları Dergisi, (18), 273-283.

Tuna, M. ve Özyurt, B. (2018). Ankara'da Gastronomi Turizminin Değerlendirilmesi: Nitel Bir Araştırma, Journal of Tourism and Gastronomy Studies, 6(Special issue), 73-87.

Yalçın Çelik, S. D. (2010). Mengen'de Özel Gün Yemekleri. Millî Folklor, 22, 86-127.

Yenipınar, U. ve Kart Gölgeli, Ü. (2015). Yerel Yiyeceklerin Gastronomi Turizmindeki Yeri ve Önemi: Anamur Örneği, I. Avrasya Uluslararası Turizm Kongresi Güncel Konular, Eğilimler ve Göstergeler, 28-30 Mayıs 2015. Konya. ss: 313-328.

Yıldırım, A. ve Şimşek, H. (2008). Sosyal Bilimlerde Nitel Araştırma Yöntemleri. (7. Baskl), Ankara: Seçkin Yayıncılık.

Zağralı, E. ve Akbaba, A. (2015). Turistlerin Destinasyon Seçiminde Yöresel Yemeklerin Rolü: İzmir Yarımadası'nı Ziyaret Eden Turistlerin Görüşleri Üzerine Bir Araştırma, Journal of Yaşar University, 10(40), 6633-6644. 